\title{
ТЕЧЕНИЕ НЕОНАТАЛЬНОГО САХАРНОГО ДИАБЕТА ПРИ МУТАЦИИ В ГЕНЕ ИНСУЛИНА (INS), МУТАЦИЯ G32S
}

\author{
Емельянов А.О., Кураева Т.Л., Губанова М.Д., Безлепкина О.Б. \\ ФГБУ «НМИЦ эндокринологии» Минздрава России, Москва
}

\begin{abstract}
Неонатальный СД (НСД) включает в себя группу гетерогенных заболеваний, при которых сахарный диабет манифестирует в первые 6 месяцев жизни. Частота НСД составляет по разным источникам от 1:160 тыс. до 1:300 тыс. новорожденных. Самыми частыми причинами НСД являются аномалии в структуре 6-й хромосомы, мутации в генах KCNJ11 и АВСС8. Только в 16\% НСД вызывается мутациями в гене INS, при которой нарушается секреция инсулина в $\beta$-клетках. Процесс образования инсулина происходит в несколько этапов, когда из его предшественника препроинсулина образуется путем отщепления части белковой молекулы проинсулин, который в аппарате Гольджи вместе с цинком упаковывается в гранулы. Изменения расположения и количества остатков аминокислоты цистеина при мутации в гене INS нарушают сворачивание препроинсулина и могут тормозить секрецию гормона. Большинство мутаций в гене INS приводят к повышению уровня циркулирующего проинсулина с легкими симптомами СД.
\end{abstract}

ЦЕЛЬ: описание клинического случая НСД с мутацией в гене INS.

Пациент А. наблюдается в ФГБУ «НМИЦЭ» с 9 мес. Ребенок от 1 беременности, с тяжелым токсикозом и угрозой прерывания беременности в 1 триместре. Роды на 37-38 нед. Вес при рождении 2770 г, длина тела 49 см. По шкале Апгар 8/8 6. Период ранней неонатальной адаптации протекал неосложненно. Грудное вскармливание до 4 мес. Наследственность: у мамы при 2 беременности — гестационный сахарный диабет ? ( $\left.\mathrm{HbA}_{1 c} 5,7 \%\right)$, СД2 у прабабушки по маме. Впервые глюкозурия выявлена случайно в 3,5 мес. В 5,5 мес. выявлена гипергликемия 30,4 ммоль/л без клинических проявлений и кетоза. При госпитализации рост 68 см (SDS +0,69), индекс массы тела 18,7 (SDS + 0,93). HbА 1с 11,8\%, С-пептид снижен (141 пмоль/л). Инициирована помповая инсулинотерапия (Mimimed 754, инсулин Лизпро). В 8 мес в течение 1-го месяца инсулинотерапию не использовали, в связи с нормогликемией. В 9 мес. психомоторное развитие по возрасту. $\mathrm{HbA}_{1 с} 7.6 \%$. Доза инсулина 1,5-2 Ед/сут (0,15-0,2 Ед/кг/сут), за счет болюсной - 0,3-0,4 Ед на каждый прием пищи, базальная отменена в связи с частым питанием. С-пептид: 1.63 нг/мл через 2 часа после еды (в пределах нормы). Выявлена мутация в гене INS (NM 000207.3) в экзоне 2 гетерозиготный вариант c.94G >A:p.G32S (rs80356664; HGMD: CM074280;ClinVarID:21122), патогенный; описан при НСД. В 9 мес рост : $76.1 \mathrm{~cm}$ (SDS 1.76), ИМТ : $17.6 \mathrm{kг} / \mathrm{M}^{2}$ (SDS 0,04).

ВЫВОды: особенностью данного случая является достаточно мягкая манифестация, стабильное течение с низкой потребностью в инсулине, наличие ремиссии заболевания на протяжении 1 мес в 8-месячном возрасте, сохраняющаяся секреция инсулина через 4 мес от начала заболевания, что отличает его от других подтипов НСД, а также от СД 1 типа. 